\title{
Glückwünsche des Rektors und des Vizerektors anlässlich des 80 . Geburtstages von em.O.Univ.-Prof. Dipl.-Ing. Dr. mont. Hans Jörg Steiner
}

Im April 2017 vollendete em.O.Univ.-Prof. Dipl.-Ing. Dr. mont. Hans Jörg Steiner das 80. Lebensjahr. Dies möchten wir zum Anlass nehmen, ihm für sein Wirken in der Wissenschaft und Lehre an der Montanuniversität Leoben zu danken.

Über einen Zeitraum von 37 Jahren leitete er als Vorstand das Institut für Aufbereitung und Veredlung an der Montanuniversität Leoben und war damit einer der längst dienenden Professoren an unserer Alma Mater. Nach seiner Emeritierung im Jahre 2005 übernahm Prof. Helmut Flachberger, ein Schüler des Jubilars, den Fachbereich Aufbereitung und Veredlung.

Mit seinen Arbeiten auf dem Gebiet der Aufbereitungstechnik hat sich Hans Jörg Steiner einen Ruf als hoch geschätzter akademischer Lehrer und Forscher weit über die Grenzen des Landes hinaus erworben. Hörer, die seine Vorlesungen besuchten und gegenwärtig in verantwortungsvollen Positionen wirken, berichten noch heute, dass sie von seinen Vorlesungen gefesselt waren und von dem vermittelten Wissen im späteren Berufsleben profitierten.

Auch auf wissenschaftlichem Gebiet waren seine Arbeiten prägend, auf einige davon möchten wir in diesem Rahmen in der gebotenen Kürze verweisen. Am Anfang der beruflichen Laufbahn von Hans Jörg Steiner stand die Flotation in der gesamten fachlichen Breite im Vordergrund. Diplomarbeit, Dissertation und Habilitation wie auch eine Reihe an richtungsweisenden Publikationen aus dieser Schaffensperiode legen Zeugnis davon ab. In der Zerkleinerung befasste er sich über mehrere Jahrzehnte mit der Auffindung stoffbedingter, von der Maschinenart unbeeinflusster Parameter zur Charakterisierung des Zerkleinerungsverhaltens, was sich in dem nach ihm benannten Konzept der "Energieoptimierten Zerkleinerungskette" niederschlug. Bahnbrechend waren Hans Jörg Steiners Arbeiten über die Natürliche Bruchcharakteristik von Gesteinen. Ganz in der Tradition von Peter Ritter von Rittinger, dem wissenschaftlichen Begründer der Aufbereitungslehre, setzte er zur Beschreibung des Zerkleinerungsvorganges die in ein Gestein eingebrachte Energie mit dem Zuwachs an Oberfläche in Verbindung. Dabei werden die "Natürliche Bruchcharakteristik" über die Korngrößenverteilung des zerkleinerten Gutes mit der höchstmöglichen Gleichförmigkeit sowie die Kenngrößen „Rittinger-Koeffi-

zient", "minimale Korngröße" und „Kornformfaktor" definiert. Ganz wesentlich ist dabei zu vermerken, dass Hans Jörg Steiner die "Natürliche Bruchcharakteristik" eines Gesteins als eine Materialeigenschaft definierte. Mit groBer Leidenschaft verfolgte er auch die apparative und methodische Verbesserung der Kleinversuchstechnik für alle Standardverfahren der Mineralaufbereitung. Über viele Jahre hat er in enormem Umfang experimentell gearbeitet und dabei eine Reihe von Laborverfahren entwickelt, um zu Berechnungskonzepten zu gelangen, die für eine Auslegung von Aufbereitungsanlagen im industriellen Maßstab herangezogen werden können. Damit hat er auch einen wesentlichen Beitrag für die Weiterentwicklung der Aufbereitungsindustrie in Österreich geleistet. Schlussendlich sei hier wegen des Bezugs zu seinem Geburtsort Eisenerz das von ihm entwickelte Konzept des "selektiv-magnetisierenden Blitzröstens von Spateisenstein" für den nahegelegenen Steirischen Erzberg besonders hervorgehoben.

Im Namen der Montanuniversität Leoben und natürlich auch in unserem Namen erlauben wir uns, Herrn em.O.Univ.-Prof. Dipl.-Ing. Dr. mont. Hans Jörg Steiner das Beste für seinen weiteren Lebensweg, insbesondere Gesundheit, Glück und Zufriedenheit, zu wünschen.

Glück auf!

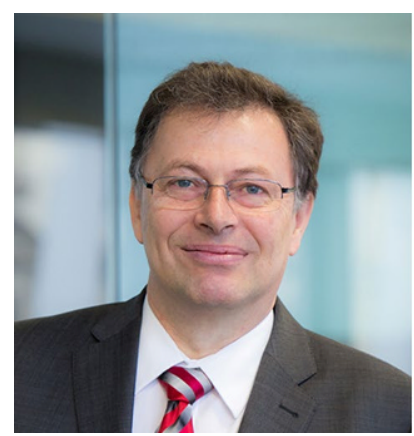

Univ.-Prof. Dipl.-Ing. Dr. techn. Dr. h.c. Wilfried Eichlseder, Rektor der Montanuniversität Leoben

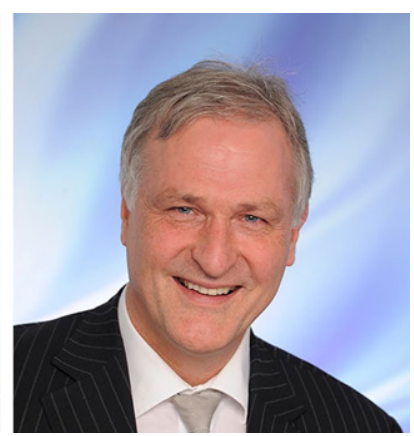

Univ.-Prof. Dipl.-Ing. Dr. mont. Peter Moser, Vizerektor der Montanuniversität Leoben 